Recibido: 14 diciembre 2015 Aceptado: 1 julio 2016

Publicado: 29 julio 2016

Cita: Ruiz González, N. (2016). «Sistema de tratamiento en el español de Canarias. Estudio sociolingüístico en una comunidad semiurbana".

Normas 6, 53-67. doi: 10.7203/Normas.6.8152

\section{Sistema de tratamiento en el español de Canarias. Estudio sociolingüístico en una comunidad semiurbana}

\author{
ADRESS SYSTEM AT SPANISH OF CANARY \\ ISLANDS. SOCIOLINGUISTICS STUDY IN A \\ SEMI URBAN COMMUNITY
}

\begin{abstract}
Natalia Ruiz González
Universidad de Granada

Resumen:

Pese al amplio volumen de estudios sobre el español de Canarias, el sistema de tratamientos es un aspecto poco analizado, en comparación con otros relacionados con el léxico o la fonología. El objetivo de este trabajo será conocer el funcionamiento de estas unidades, tanto las formas pronominales como las formas nominales, en los ámbitos familiar, escolar, social y laboral, en la localidad tinerfeña de La Orotava y demostrar a través de su estudio la vigencia de un sistema asimétrico de tratamiento en las islas, así como comparar el uso de estas unidades en función de factores sociales como la edad, el sexo o el nivel de instrucción de los hablantes. Desde la sociolingüística, nuestra investigación tratará de ofrecer unas pautas sobre los comportamientos o relaciones sociales que se producen en estos contextos y que se manifiestan a través de la lengua.

Palabras clave: sociolingüística, sistema de tratamiento, formas pronominales, formas nominales
\end{abstract}

Abstract:

Despite the large volume of studies about the Spanish of Canary Islands, the address system has been a bit analyzed theme in comparison with lexicon or phonology. The purpose of this study is to knowing the pronominal and nominal forms in different contexts: family, school and social and labor spheres, in a semi urban community of Tenerife called La Orotava and to demonstrate the state of being in force of an asymmetric address system in the islands. Moreover, we are going to compare the use of these units according to social factors such as age, sex or education level of the speakers. Through a sociolinguistics perspective, our research is going to discover the social relationships on these contexts.

Keywords: sociolinguistics, address system, pronominal forms, nominal forms 


\section{INTRODUCCIÓN}

\subsection{Presentación e hipótesis}

La sociolingüística tiene como objetivo principal describir la relación existente entre unos procesos lingüísticos y unos procesos sociales determinados (Bosch 1985: 163). Puesto que las formas de tratamiento representan un uso de la lengua vinculado directamente a factores sociales como la edad o la confianza, usaremos esta metodología para investigar el sistema de tratamientos pronominal y nominal que existe en una localidad de Tenerife llamada La Orotava.

Los trabajos sobre formas de tratamiento en el español de Canarias son escasos si se compara con el interés que han suscitados otras áreas de esta variedad dialectal desde la segunda mitad del siglo XIX (Medina López 2010: 225), especialmente el léxico y la fonética. Así pues, el estudio de dichas formas lo inaugura Medina López con la investigación de varias comunidades juveniles en Tenerife y Gran Canaria durante 1990 y 1991, y se reafirma con la tesis de este mismo autor sobre el tratamiento pronominal en una comunidad rural tinerfeña Buenavista del Norte y con la de Rodríguez Mendoza sobre una región semirrural, San Sebastián de La Gomera. Ambos trabajos fueron publicados en 1993. Con posterioridad ha habido varias investigaciones destacadas sobre los tratamientos en Canarias como el estudio de las formas nominales en Fuerteventura de Morera (1991) o el de las formas pronominales en Las Palmas de Gran Canaria de Morín (2001).

Las hipótesis sobre las que partimos para nuestra investigación son las siguientes:

- El uso de tú (T) es mayor que el de usted $(V)$ en las generaciones más jóvenes, en las mujeres y en los hablantes de nivel educacional alto.

- Sigue vigente un sistema asimétrico de tratamiento, vinculado más a las diferencias generacionales entre hablantes que a las diferencias sociales de los mismos.

- Este trato asimétrico afecta tanto a las formas pronominales como a las nominales en cuanto se influyen mutuamente.

Tomándolas como referencia y con el fin de verificarlas o rechazarlas, indagaremos en el uso de las formas pronominales y nominales de tratamiento en dicha localidad.

\subsection{Comunidad estudiada}

La Orotava es un municipio situado al norte de la isla de Tenerife que ocupa gran parte del llamado Valle de la Orotava, uno de los principales enclaves económicos de la isla.

Tiene una extensión de 207,31 km² que lo convierten en el mayor de los municipios tinerfeños y una población de 41255 habitantes (INE, 2013) que lo hacen el quinto núcleo de mayor población de la isla. Aunque el principal centro de población apenas alcanza los 390 metros de altitud, la del municipio va desde el nivel del mar hasta los 3718 metros de la cima del Teide situada dentro del término municipal.

El principal núcleo de población es La Orotava o «La Villa» con 17705 habitantes (ISTAC, 2005). Sin embargo, existen otros núcleos o barrios con importante densidad de población dentro del municipio, tal es el caso de La Perdoma con 4336 habitantes (ibíd.), San Antonio con 2137 (ibíd.) o La Florida con 1465 (ibíd.), entre otros ${ }^{3}$.

${ }^{3}$ Estos datos han sido recogidos de La Orotava.

Datos demográficos, en :

<http://www.tenerifevioleta.es/diagnosticonecesidades/pdf\%20municipios/LA\%20OROTAVA.pdf>. 


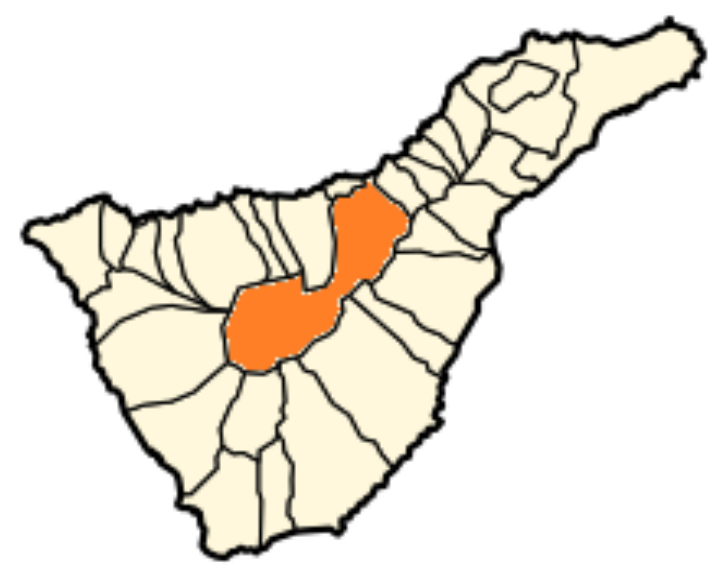

Imagen 1: Situación geográfica de la localidad

\subsection{Introducción}

Las formas de tratamiento constituyen uno de los temas más estudiados por la sociolingüística pues su uso está claramente ligado a la estructura social y se rige por las normas y conductas impuestas por esta (Medina López 1989-90: 249).

Se conoce con este nombre a las variantes pronominales y nominales que se eligen para dirigirse a un destinatario en función de la relación social entre este y el hablante (RAE 2009: 1250). En la elección de una forma determinada intervienen numerosos factores. Los más destacados son el grado de confianza existente entre los interlocutores, la diferencia generacional entre ambos, el grado de formalidad de la conversación y el nivel o respeto que imponga quien recibe el trato (ibíd.). Las formas pronominales solo distinguen dos variantes: la llamada forma de respeto usted y la forma de confianza o familiaridad, tú, o vos según el ámbito dialectal hispánico que se estudie. Canarias igual que el resto de España no es una región voseante así que solo podremos tener en cuenta los estudios sobre usted y tú.

Los pioneros en estudiar las formas de tratamiento desde un punto de vista sociolingüístico fueron Brown y Gilman con su trabajo «The pronouns of power and solidarity» (Blas Arroyo 1995: 230) de la década de los sesenta. Para ellos existen dos ejes semánticos que determinan la evolución de los pronombres de tratamiento en lenguas como el español; estos son el eje de poder y el de solidaridad (ibíd.):

- $\quad$ El eje de poder, por un lado, determina que uno de los hablantes que interviene en el acto de habla es capaz de controlar la conducta del otro. Se trata de una relación asimétrica o no recíproca en la cual el hablante situado en nivel superior recibirá la forma cortés y respetuosa usted (V) y usará hacia el interlocutor ubicado en nivel inferior la forma tú (T) (Brown et al. 1960: 255).

- El eje de solidaridad marca las relaciones de parentesco, de confianza o de pertenencia al mismo grupo (de edad, clase social, etnia, etc.). Establece entre hablante y oyente una relación simétrica mediante $T$ que en algunos casos se desplaza a $V$ cuando la solidaridad es menor. En resumen, los hablantes usan y reciben la misma forma de tratamiento (257-58).

Brown y Gilman vaticinaron, además, un cambio progresivo de las relaciones sociales, que pasarían de ser marcadamente asimétricas a simétricas (apud Medina López 1990: 630). Este cambio lingüístico viene ligado a un cambio social mayor por el cual las sociedades tienden hacia la igualdad desterrando símbolos que supongan barreras sociales, ideológicas o lingüísticas (Medina López 1989-90: 257) como el ustedeo. Estas innovaciones han sido, en su mayoría, bien acogidas por los lingüistas salvo para quienes predicen la muerte del usted con ellas. Uno de los más agoreros al respecto ha sido Alonso que recuerda épocas mejores de las formas pronominales: «El tú era entonces un verdadero tú: para Dios, para nuestra familia, para la sabrosa y sedimentada intimidad.» (1968: 267). 
Lo mismo hace Marcos Marín que alaba el uso reiterado de usted en otras regiones hispánicas mientras en España este pronombre estaría sufriendo un importante descenso por el abuso que se hace del tú, "en parte por la ola de mal gusto y pérdida de respeto que avanza sobre la vida española» (1972: 146).

Culpable de esa progresiva extensión del tuteo son -según Alonso- las mujeres, quienes más innovan en la lengua (1968: 265) y quienes modernizan las costumbres de la sociedad (da Silva, 2006: 2182).

Sin embargo, pese a la situación agónica que viviría el usted según ellos, el hecho es que cada vez es más frecuente el uso recíproco de esta misma forma; no como ocurría antes, por una relación de poder entre hablante y oyente, ni por un posible retroceso de la solidaridad, sino por la prevalencia de un factor más importante: lo que Brown y Levinson (1978) llamaron distancia social (apud Blas Arroyo 1995: 233).

Este nuevo rasgo se considera determinante en las estrategias discursivas que emplea el hablante para preservar, tanto la imagen pública y privada del interlocutor como la suya propia y sus intereses, de lo amenazante que resulta cualquier acto de habla (Havertake 1994: 18).

Por tanto, podemos afirmar que el sistema de tratamientos de las lenguas naturales ha cambiado desde la segunda mitad del siglo XX y ha dejado de ser un sistema marcado por las relaciones de poder a otro donde factores como la distancia social o la solidaridad determinan el uso recíproco del mismo pronombre: usted o tú, respectivamente. Además, esto contradice cualquier teoría fatalista que creyera que esos cambios supondrían la muerte de una de las dos formas, especialmente la de distancia, como ocurriera en inglés con thou ('tú') y you ('usted') aunque a la inversa (Alonso 1968: 266). Thou ahora se reserva para la poética pero en el pasado era la forma de tratamiento familiar para una persona (Brown et al. 1960: 253).

En Canarias en la actualidad se utilizan el pronombre tú como forma de tratamiento informal o de confianza para la segunda persona del singular y ustedes para la segunda persona del plural; y como formas formales o de respeto usted, en singular, y ustedes, en plural.

\begin{tabular}{|l|c|c|}
\cline { 2 - 3 } \multicolumn{1}{c|}{} & Confianza o informal & Respeto o formal \\
\hline Singular & Tú & Usted \\
\hline Plural & \multicolumn{2}{c|}{ Ustedes } \\
\hline
\end{tabular}

Tabla 1: Sistema pronominal del español de Canaria

Aun así, en áreas rurales de La Gomera, El Hierro y La Palma se mantiene, según Diego Catalán (apud Fontanella de Weinberg 2000: 1403) el uso de vosotros y del pronombre átono os (o el arcaico vos) como formas de tratamiento para la segunda persona del plural familiar.

En Canarias, tradicionalmente se ha tuteado solo a los interlocutores más íntimos y a las personas consideradas socialmente inferiores. Por tanto, se ha reservado la forma $\mathrm{V}$ para hablar con superiores, con desconocidos, con personas mayores o con los ascendientes (Morera 1990: 41). Hasta finales del siglo XIX, en muchas zonas se usa su merced para las clases altas y aún en 1932 lo recogen los hermanos Millares Cubas (apud Morera 1990: 41). En la actualidad ha desaparecido totalmente y solo se usa usted.

Los superiores que para el canario son, según Morera (43), "casi todos los mortales, excepto sus paisanos y parientes allegados", solo usan usted para dirigirse a su interlocutor cuando pretenden distanciarse de él o reñirlo.

Teniendo esto en cuenta, las formas de tratamiento pueden dividirse, además, en formas de tratamiento estables o permanentes y formas variables o circunstanciales. Las primeras son las se usan para dirigirse a una persona en cualquier situación y circunstancia como el trato de $V$ a los suegros, por ejemplo; mientras las segundas varían en función de la situación comunicativa, como el trato nominal a la pareja durante un enfado o delante de desconocidos (RAE 2009: 1250) o el trato de $\mathrm{V}$ a los niños como muestra de regaño. Ese tratamiento de respeto usado a personas con quien normalmente usaríamos tú representa una retirada de la confianza y se documenta ya en el siglo XVIII y principios del XIX (Lapesa 1970: 149). 


\section{2 Ámbito familiar}

«En el español actual -dice la Real Academia (2009: 1252)- es habitual el trato mediante tú (T) entre parientes cercanos, colegas y profesionales en el interior de algún organismo; y entre jóvenes». Sin embargo, no siempre fue así. En la relación entre padres e hijos, hasta la primera mitad del siglo XX, lo común era tratar a los progenitores de usted $(\mathrm{V})$. Ahora, ese uso queda relegado a zonas rurales o a hablantes de tercera generación. Como dice Medina López (1989/90: 250):

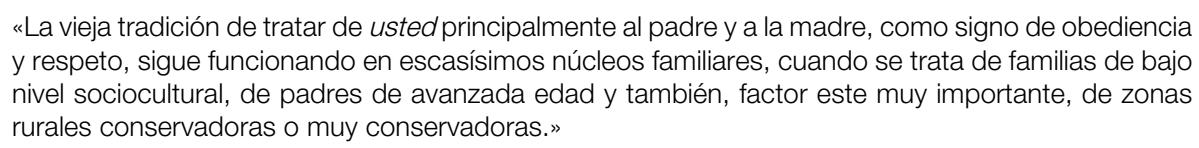

En la relación abuelo-nieto, por otro lado, también era frecuente la relación asimétrica, pero «son más las áreas lingüísticas en las que se mantienen para dirigirse a los suegros» (RAE 2009: 1256). Este cambio de tratamiento está íntimamente ligado al que se produce entre padres e hijos y en la misma dirección. Los factores que determinan el uso de T son el afecto y la confianza mientras los que mantienen $V$ lo hacen por respeto, edad y tradición (Alba de Diego et al. 2009: 32).

Las formas nominales estandarizadas que los hijos usan para dirigirse a los padres son papá y mamá (Carricaburo 1997: 51), que se adoptan a partir del siglo XVIII por influencia francesa (López Vallejo 2010: 588) y que en Canarias solo se escuchan en zonas urbanas (Morera 1990: 83). Sus alternativas son pa, papi, papito y papaíto y ma, mami, mamita, mamaíta. Las formas padre y madre, antes predominantes, se usan ahora con sentido humorístico o irónico, mientras viejo/a es un vocativo cariñoso usado para referirse a los padres mamá (Carricaburo 1997: 51). En España esta última forma ha sufrido un importante contagio en uso referencial entre un grupo social concreto: jóvenes varones de nivel socioeducacional medio (López Vallejo 2010: 579).

Los padres tratan comúnmente a los hijos por su nombre de pila o mediante apodos. Pueden usar la variante hijo, -a posponiendo el posesivo o, en algunos casos, usando complementos como de mi vida, de mi alma, etc. (Beinhauer 1963: 35); aunque cada región usa unas formas cariñosas concretas. Por ejemplo, en España se emplean niño, muchacho, nene, chaval, peque, diablillo, chiqui, gordi, entre otras (Carricaburo 1997: 51).

Los nietos utilizan abuelo, abue, abu o la forma con diminutivo abuelito para referirse a los padres de sus padres. Y de estos pueden recibir el nombre de pila, un hipocorístico o cualquier forma cariñosa de las que hemos apuntado para los padres.

En las relaciones amorosas, los novios o esposos emplean, además de sus nombres de pila o hipocorísticos, nombres o vocativos cariñosos como alma, amor, mi querido/-a, cielo, bonito, lindo, viejo/-a (extendido en las clases bajas), jefe/-a (con sentido irónico); siendo el más extendido, según Beinhauer (1963: 36) el calificativo vidita, aunque depende mucho de la situación y el contexto comunicativo. Otras formas cariñosas son precioso, preciosa, preciosidad, rey, reina o cualquier nombre común acompañado de un genitivo atributivo del tipo de mi alma, de mi vida, de mi corazón, etc. (ibíd.). Otro tipo de vocativos que se emplean en estas relaciones se consiguen añadiéndole a insultos o improperios como tonto, pillo o pícaro sufijos diminutivos. El resultado son formas como tontín, tontito, pillín, picaruelo, etc. (38).

En lo que respecta a otras relaciones de parentesco, destaca el uso de unos determinados vocativos con un significado distinto al que tienen generalmente: primo y tío (con el valor de 'tipo'). Los jóvenes de sexo masculino son los que más lo usan, incluso para llamar a los padres (33).

\section{3 Ámbito social}

Mucho se ha hablado del trato pronominal entre padres e hijos o abuelos y nietos, pero fuera de la esfera familiar es difícil encontrar datos sobre las preferencias de los hispanohablantes en otros contextos, como en el ámbito social, aunque este sea el grupo donde se detecta mayor índice de formalidad ya que se incluye aquí el trato a desconocidos o a personas de cierto estatus como los médicos (Almeida et al. 1994: 172).

En el ámbito social hay que distinguir tres grandes grupos según el grado de intimidad entre los hablantes: en un primer estadio se encuentran los amigos cercanos donde el grado de confianza e intimidad es mayor, en un segundo grupo los conocidos o los vecinos y en un tercer nivel el resto de personas con las que establecemos contacto habitualmente y que, en cualquier momento, por el aumento de la confianza y la familiaridad, pueden pasar a cualquiera de los otros dos. En este 
último grupo se incluye el médico de cabecera, el cartero, el dependiente de las tiendas en las que el hablante compra o el cura de la iglesia a la que acude si es católico.

Con el último grupo de personas se suele establecer una relación de poder en la que el hablante puede situarse en una posición inferior o superior. Por ejemplo, en el trato con el médico o el cura se sitúa inferior socialmente pues estos tienen mayor poder e influencia social, mientras que en el trato con un dependiente o un camarero el hablante se encuentra en una escala superior porque estos están a su servicio. Sin embargo, debido a la progresiva pérdida de significación de las relaciones de poder a favor de la solidaridad, el uso de los pronombres hacia los interlocutores con distinto estatus al hablante ha variado (Almeida et al. 2006: 258): así, a los camareros, antes tratados con $\mathrm{T}$ por ser entendidos como inferiores socialmente, ahora se les suele tratar con $\mathrm{V}$, mientras a los sacerdotes, tratados tradicionalmente con $\vee$ por estar en un estrato superior, ahora se les ofrece T (ibíd.).

Para llamar a los amigos o conocidos las formas usadas dependerán en muchos casos del sexo del emisor y del receptor. Así pues, entre mujeres se emplean popularmente las formas chata, chatilla, guapa, cielo o encanto y chica, tía, loca o gordi si son jóvenes o adolescentes (Carricaburo 1997: 55). Entre hombres adultos se pueden escuchar macho, cabrón o cabroncete y tronco, tío o colega entre los más jóvenes (ibíd.). Las mujeres llaman a los hombres con formas como guapo o majo mientras ellos -como distinción de respeto- prefieren el nombre de pila o un apodo para llamar a las mujeres (56).

Para los desconocidos, las personas de cierta edad o las que tienen un cargo superior al del hablante en la escala social, se utilizan distintas formas respetuosas de tratamiento nominal. Por un lado, es habitual el uso de don o doña seguido del nombre de pila aunque no es infrecuente también su uso con diminutivos e hipocorísticos (RAE 2009: 1258). Este don expresa una "estimación subjetiva de respeto e intimidad al mismo tiempo» (Beinhauer 1963: 36). Por otro lado, está el caso de señor o señora (incluyendo la forma señorita para mujeres solteras) que precede a nombres de pila o apellidos y constituye una forma de tratamiento mucho más cortés que la anterior.

Para los cargos religiosos se utiliza el nombre padre o madre antepuesto a un nombre de pila, pero también son formas habituales fray (apócope de fraile) para hombres y sor o hermana para mujeres (ibíd.).

El título doctor no suele emplearse como forma de tratamiento salvo para hablar con los médicos (37) con quienes no constituye propiamente un título sino un caso de tratamiento por el nombre profesional.

Por último, destaca en Tenerife el uso de cristiano como forma cortés de tratamiento, que según Alvar (1959: 52) se usa indistintamente con el valor de 'usted' o 'señor'. En la actualidad, se emplea para hacer reproches con cierto respeto (Morera 1990: 82), incluso a familiares o amigos.

\section{4 Ámbito social}

Lo común en el ámbito laboral es el uso de una forma de tratamiento estable para hablar a las personas de las que el hablante depende profesionalmente y con las que se relaciona a diario, aunque todo depende siempre de la formalidad de la situación (RAE 2009: 1256).

Por una parte, pronominalmente lo más frecuente es el uso de $\mathrm{V}$ para dirigirse a las personas superiores laboralmente y recibir de estos $\mathrm{T}$, aunque este último tratamiento registra una significativa inseguridad lingüística (Almeida et al. 1994: 171); es decir, en esta elección influyen, además del poder, otros factores como la edad del receptor o el grado de confianza existente entre ambos interlocutores. Aun así, lo más común es que con los compañeros se establezca un trato solidario, y se emplee recíprocamente $T \circ \vee$ según la cercanía entre emisor y receptor, mientras a los subalternos se les ofrece $T$ y se recibe de ellos $V$.

Por otra parte, las formas nominales respetuosas que emplean los hablantes para llamar o hacer referencia a un superior son don o doña y señor o señora. Otra forma que suele actuar como vocativo en estos casos es el título jefe o jefa, mucho más informal que las anteriores pero que denota aún una relación asimétrica entre hablantes. El único trato igualitario sería el mutuo intercambio del nombre de pila.

Para los compañeros de trabajo pueden emplearse cualquiera de las formas nominales que hemos comentado, en función de la edad, la confianza, etc. La forma característica de este ámbito sería el uso de los sustantivos colega, compañero o camarada en forma apelativa. 


\section{5 Ámbito escolar}

Como ocurría con el ámbito laboral, en el ámbito escolar, cualquiera que sea su nivel, se establecen dos tipos de relaciones. Por un lado, se crea una relación asimétrica con el educador y, por otro, una simétrica con los compañeros de clase. Por tanto, lo habitual será ofrecer a los primeros $V$ y recibir de ellos $\mathrm{T}$, e intercambiar $\mathrm{T}$ recíprocamente con los segundos o $\mathrm{V}$ si la distancia personal y generacional es muy grande. Sin embargo, dice Medina López (1989/90: 255) que el tratamiento a los profesores depende en muchos casos de factores como su edad, el grado de confianza entre ellos y sus alumnos o el tamaño mayor o menor del grupo, significando esto que cuanto menor sea la diferencia entre ambos interlocutores en algunos de estos aspectos, mayor será el uso de T. Podemos distinguir, además, la variación del pronombre según el nivel educativo, siendo el uso de T propio de los cursos superiores (Alba de Diego et al. 2009: 37).

Nominalmente, para llamar a los educadores, el hablante-alumno emplea diferentes formas según el nivel de instrucción en el que se encuentre. En el colegio, se emplea el título maestro que expresa una estimación familiar hacia el interlocutor y que también se emplea para nombrar a artistas o artesanos (Beinhauer 1968: 37), mientras que en el instituto es habitual el uso del título profesor o profesora (y su forma apocopada profe), y en la universidad dependerá del nivel de formación que los docentes hayan alcanzado pues si solo tienen el título universitario se les designará también con el sustantivo profesor mientras que si han hecho un doctorado se les llamará doctor o doctora; sin embargo, dice Carricaburo (1997: 61) que «en España doctor solo se utiliza como vocativo para los médicos" $y$, aunque profesor se usa frecuentemente como apelativo, es más destacado el uso del nombre de pila o de un nombre propio precedido de la forma don o doña (Alba de Diego et al. 2009: 37).

Entre los compañeros y el hablante se produce un intercambio solidario de formas nominales. Las más habituales son el nombre de pila, el apellido o un apodo.

\section{ASPECTOS METODOLÓGICOS Y SELECCIÓN DEL CORPUS}

La mayoría de los estudios sobre formas de tratamiento se aplican a zonas urbanas y algunos pocos a áreas rurales como los trabajos de Moreno Fernández (1986) y Medina López (1993) (Medina Morales 2010: 28). Por eso, resulta de esmerado interés lingüístico estudiar un área semiurbana como la localidad tinerfeña de La Orotava.

En la investigación hemos empleado un método de carácter cuantitativo. La obtención de los datos se llevó a cabo mediante un cuestionario aplicado durante los meses de febrero y marzo de 2014 a un total de treinta y seis informantes. El cuestionario tomó como referencia los estudios del PRESEEA (Proyecto para el estudio sociolingüístico del español de España y de América) y el estudio del sistema de tratamientos en San Sebastián de La Gomera de Rodríguez Mendoza (1993). A través de él se buscó discriminar qué forma pronominal y qué forma nominal usan los hablantes en diferentes ámbitos sociales y en diferentes contextos situacionales. Los ámbitos estudiados son el familiar, escolar, laboral y social. Dentro de cada uno se tienen en cuenta distintos tipos de receptores que clasificamos según la edad y según la confianza existente con el hablante.

El interés por conocer, además del uso de las formas pronominales, el empleo de formas nominales radica en el hecho de que las investigaciones sobre este tipo de tratamientos son escasas, tanto las sincrónicas como las diacrónicas, posiblemente porque las formas nominales presentan un inventario muy abundante y dependen en muchos casos de estrategias del discurso (Medina Morales 2010: 44).

Hemos utilizado un cuestionario semiabierto donde abundan las preguntas cerradas como ¿Cómo trata a su padre, de tú o de usted? y otras más abiertas como ¿Cómo llamas a tu hermano?. El uso de un cuestionario prefijado tiene ventajas e inconvenientes. Entre las primeras se encuentra el hecho de que nos permite obtener resultados cuantificables de manera sistematizada; entre las segundas, la falta de naturalidad con que se ofrecen los contextos y lo difícil que es para los entrevistados imaginar las situaciones por las que se pregunta (Paredes 2010: 180).

Durante su aplicación se tuvieron en cuenta las relaciones reales de los hablantes con los destinatarios por los que se les pregunta. Si, por ejemplo, un hablante no tiene pareja no le interrogaremos por el trato que ofrece a esta o a sus suegros.

Para la investigación, seguimos el modelo sociolingüístico, esto es, estudiamos una variable lingüística dependiente, el uso de la forma de tratamiento de respeto o el de la forma de tratamiento 
de confianza, en relación a distintas variables sociales independientes. Las escogidas para nuestro estudio son el sexo, la edad y el nivel educacional de los hablantes.

Para la elección de los informantes, seguimos las directrices que determina el PILEl (1973) en su Cuestionario en materia de generaciones, es decir, establecemos tres grupos etarios: un primer grupo al que llamaremos primera generación correspondiente con hablantes entre 20 y 34 años, una segunda generación con individuos entre 35 y 54 años y un tercer grupo o tercera generación con 55 o más años. Así pues, teniendo en cuenta esta subdivisión previa, la población del municipio a estudiar (mayor de 20 años) se distribuye de la siguiente forma:

\begin{tabular}{|c|c|r|r|r|}
\hline $\begin{array}{c}\text { Generación/ } \\
\text { Sexo }\end{array}$ & Hombres & Mujeres & Total & $\%$ \\
\hline I & 4208 & 4180 & 8388 & 25,44 \\
\hline II & 6881 & 7000 & 13881 & 42,10 \\
\hline III & 4947 & 5757 & 10704 & 32,46 \\
\hline N & 16036 & 16937 & 32973 & 100 \\
\hline
\end{tabular}

Tabla 2: Datos sobre la población >20 años de La Orotava según el INE ${ }^{4}$ (2013)

Como ya hemos dicho, tenemos en cuenta también el nivel de instrucción de los hablantes. Para clasificarlo, hemos atendido a la información censal sobre datos relativos al nivel de instrucción que proporciona el INE y agrupamos a los individuos en tres grandes grupos educacionales: enseñanza básica, enseñanza media y enseñanza superior, como se puede observar en la siguiente tabla:

\begin{tabular}{|c|c|c|}
\hline Nivel de instrucción & $\%$ & Total \\
\hline $\begin{array}{l}\text { Enseñanza básica } 0 \text { sin } \\
\text { estudios }\end{array}$ & 73,7 & 17146 \\
\hline Enseñanza media & 17,3 & 5704 \\
\hline Enseñanza superior & 9,0 & 2968 \\
\hline Total & 100 & 32973 \\
\hline
\end{tabular}

Tabla 3: Datos del INE sobre el nivel educacional de la población de La Orotava según el censo de 20015

La elección de la muestra la llevamos a cabo tomando los postulados del modelo de estratificación de Labov por el cual el 0,025\% de una población igual o superior a cien mil habitantes es lo suficientemente representativa para revelar las preferencias lingüísticas de dicha población. Sin embargo, la localidad que estudiamos apenas supera los cuarenta y un mil habitantes y la aplicación de dicha fórmula resulta insuficiente pues da una muestra estimativa de apenas diez hablantes. Además, aunque inicialmente pensamos en la aplicación de una muestra por cuotas con afijación proporcional, esto es, representativas del censo poblacional; siguiendo al PRESEEA, nos decidimos por una muestra por cuotas con afijación uniforme. Así, optamos por trabajar con treinta y seis informantes, un 0,088 \% del total de la población que se distribuye según la tabla siguiente:

\footnotetext{
${ }^{4}$ Estos datos se han extraído de Cifras oficiales de población resultantes de la revisión del Padrón municipal a 1 de enero de 2013, disponible en:

<http://www.ine.es/jaxi/menu.do?type=pcaxis\&path=\%2Ft20\%2Fe260\%2Fa2013\%2F\&file=pcaxis\&N=\&L=0>.

${ }^{5}$ Los datos censales fueron obtenidos de La Orotava. Datos demográficos, disponible en:

<http://www.tenerifevioleta.es/diagnosticonecesidades/pdf\%20municipios/LA\%20OROTAVA.pdf>. 


\begin{tabular}{|lr|r|r|r|r|r|}
\cline { 2 - 7 } \multicolumn{1}{c|}{} & \multicolumn{4}{c|}{ Hombres } & \multicolumn{3}{c|}{ Mujeres } \\
\cline { 2 - 7 } & . E. & M. & S. & B. & M. & \multicolumn{1}{c|}{.S. } \\
\hline Primera generación & 2 & 2 & 2 & 2 & 2 & 2 \\
\hline Segunda generación & 2 & 2 & 2 & 2 & 2 & 2 \\
\hline Tercera generación & 2 & 2 & 2 & 2 & 2 & 6 \\
\hline Total & 6 & 6 & 6 & 6 & 6 & 2 \\
\hline
\end{tabular}

Tabla 4: Datos sobre la selección final de informantes

Por cuestiones de tiempo, especialmente, la selección de los individuos fue no aleatoria. Hemos empleado la técnica conocida como «bola de nieve» según la cual partimos de amigos y conocidos así como familiares suyos para la elección de los informantes (Almeida et al. 2006: 260), creando un sistema mixto entre el modelo de «red social» y el modelo de clases.

Una vez obtenidos los datos fueron sometidos a tratamiento estadístico (tablas de frecuencia y de contingencia) con el programa SPSS para Windows7.

\section{INTERPRETACIÓN DE LOS RESULTADOS}

Las formas $\vee$ y $T$ son usadas conjuntamente por el grueso de los hablantes (un 52,8 $\%$ de la primera frente a un $47,2 \%$ de la segunda) pues, aunque ha aumentado el empleo de $T$ en el tratamiento entre padres e hijos o maestros y alumnos, $V$ es la forma más utilizada para dirigirse a desconocidos, independientemente de su estatus o de su edad. Por otro lado, la reducción de poder y el aumento de solidaridad en las relaciones contribuyen a un intercambio mutuo del pronombre $\mathrm{V}$ (hasta en un $38,7 \%$ de los casos), como sucede entre jefe y subalterno. Esto se demuestra en el alto porcentaje de hablantes que se influencian por el trato previo que les da su interlocutor (un 38,9\% de los hablantes que son tuteados frente a un $58,3 \%$ de los que son tratados con V) o que dudan seriamente entre usar V y T (36,1 \% de los informantes). Como dice Hernández Alonso (1970: 272):

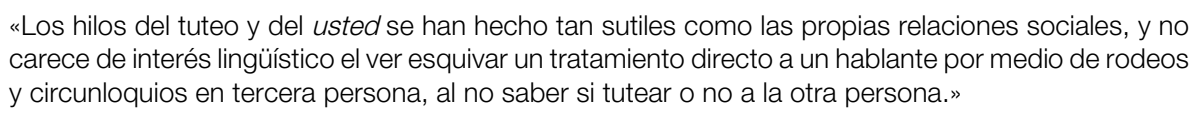

Aun así, una amplia mayoría prefiere recibir T de sus interlocutores (91,7 \%), lo cual puede deberse al afán posmoderno de querer parecer eternamente joven que en las últimas décadas ha experimentado la población occidental; esto es, si los hablantes con los que interactúo me tratan con $\mathrm{T}$, significará que soy o parezco lo suficientemente joven para no recibir $\mathrm{V}$.

Son hablantes varones los que difieren generalmente entre $\vee$ y T según el sexo (hasta un 13,9 \%), pues según estos mismos señalan socialmente «las mujeres merecen un trato más elevado, lejos de apodos y del tuteo irrespetuoso". Contrario es el caso de los niños, que merecen, según los hablantes, sobre todo las mujeres, más maternales y afectivas, un tratamiento cercano y cariñoso en un $69,1 \%$ de los casos. En cuanto a las diferencias sociales, el porcentaje de hablantes que distingue el trato según el nivel o estatus de su interlocutor es aún elevado (19,4\%), incluso en hablantes de las primeras generaciones que podrían haber visto incrementadas dichas diferencias a raíz de la crisis económica actual.

\section{1 Ámbito familiar}

En el ámbito familiar podemos distinguir dos tipos de relaciones claramente diferenciadas, por un lado, las de tipo asimétrico y por otro, las de tipo simétrico. Dentro de cada una de ellas, la relación entre hablante y oyente es distinta según el grado de cercanía entre los interlocutores.

En el eje asimétrico se encuentran las relaciones entre padre e hijo, abuelo y nieto, suegro y yerno o padrino y ahijado, entre otras. En ellas, observamos una clara disminución del pronombre $V$ en las generaciones más jóvenes (apenas un 5,6\% que, además, corresponde con casos de hijos que carecen de relación con sus padres) mientras la tercera generación es la única que ustedea en su totalidad a sus ascendientes, ya sean sanguíneos o políticos. 
Se trata de un cambio progresivo iniciado ya a finales del siglo XIX y que ha tenido su culminación en las últimas décadas, como dice Lázaro Carreter (1997: 429):

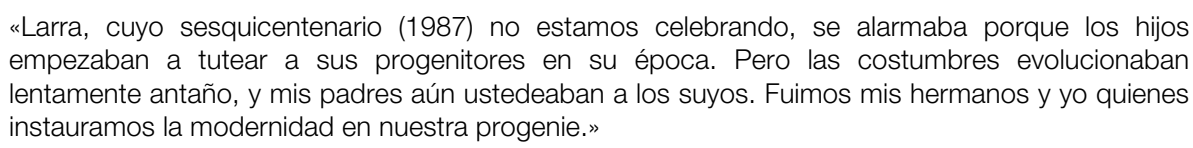

Además, ese tuteo se corresponde con hablantes de primera y segunda generación y de nivel educacional alto preferentemente, tal como señala Miguel Calderón Campos (1999: 10):
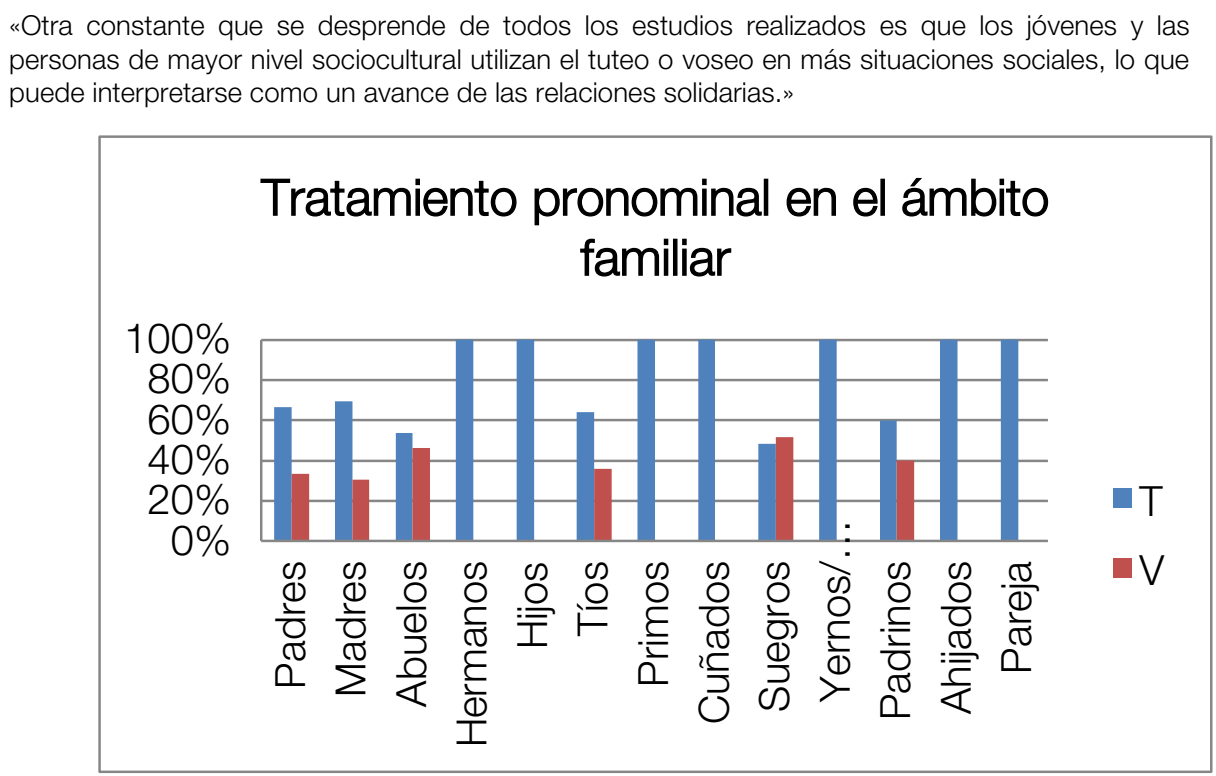

Gráfico 1: Trato pronominal en el ámbito familiar

En el lado opuesto se encuentra la relación de los informantes-padres hacia sus hijos que prefieren la forma $T(100 \%)$ frente a $\mathrm{V}$, que se considera en desuso o de empleo ocasional para regañar a la prole o ironizar con su comportamiento; y además, utilizan generalmente el nombre de pila o formas afectivas como diminutivos para dirigirse a ellos nominalmente en detrimento de nombres de parentesco como hijo/a o nombres de edad como joven, que indicaban una mayor distancia social. Sin embargo, el uso de las formas papá, pa o papi por parte de sus hijos es resultado de la vigencia de un sistema asimétrico de tratamiento. Las relaciones suegro-yerno o padrino-ahijado, en cambio, solo se mantienen asimétricas si la confianza entre hablante e interlocutor es muy baja.

El uso que los hablantes hacen de las formas nominales es diverso. Para los padres se prefiere papi/mami $(23,3 \%)$ o la forma apocopada pa/ma $(40,5 \%)$. La primera avanza como forma de tratamiento en los hablantes jóvenes mientras la segunda es característica de los hablantes de la tercera generación de cualquiera que sea su nivel sociocultural. En situaciones concretas como una petición o un ruego, los hablantes recurren a las formas diminutivas para aminorar su demanda. En cuanto a los abuelos, lo más común es el empleo de la forma abuelo/a $(80,1 \%)$ que puede ir o no acompañada del nombre de pila del mismo pero, además, es significativo el uso de las formas papá/mamá o padre/madre seguidas del nombre de pila para llamar a los padres de sus padres. Este uso $(8,45 \%)$ es propio de los hablantes de tercera generación aunque también se recoge en hablantes de la segunda; por tanto, se encuentra actualmente en desuso del tratamiento nominal. Sobre ellas dice Carricaburo (1997: 54) que están «muy extendidas en Hispanoamérica para designar a los abuelos» por lo que podríamos hablar de un resquicio de la mutua interferencia entre Canarias y América.

En el eje de las relaciones simétricas, destacan las relaciones fraternales o amorosas donde es exclusivo el uso de $\mathrm{T}$, incluso en situaciones atípicas como un enfado o la presencia de desconocidos. En cuanto a las formas nominales, el trato más generalizado entre estos familiares es el nombre de pila y sus formas diminutivas, así como hipocorísticos y algún sobrenombre o apodo para las primeras, y estas mismas formas y otras de tipo cariñoso como mi amor o mi vida para las segundas. Es curioso el uso de la forma hermana/o (6,6\%) para dar un matiz emocional a la 
conversación o el de las formas de trato filial papi/mami o papá/mamá entre esposos (8,4\%) derivado de la intención de facilitar a los hijos el aprendizaje de dichas formas.

Otras relaciones de carácter simétrico son las que se mantienen entre cuñados o primos, siendo de especial importancia el comentario de uno de los hablantes de tercera generación sobre estos últimos: "antes a los muy mayores de usted pero lo normal es de tú», mostrando su conciencia lingüística sobre el cambio que se ha producido en el sistema de tratamientos. Lo común en ellas, en cuanto al trato nominal, es el uso del nombre de pila (69,3\%) o, en su defecto, de las formas de parentesco cuñado (y su apócope cuñi), en un 18,2\% de los casos, y primo, en un $20 \%$, que se utilizan para manifestar 'festividad' o «vacilón».

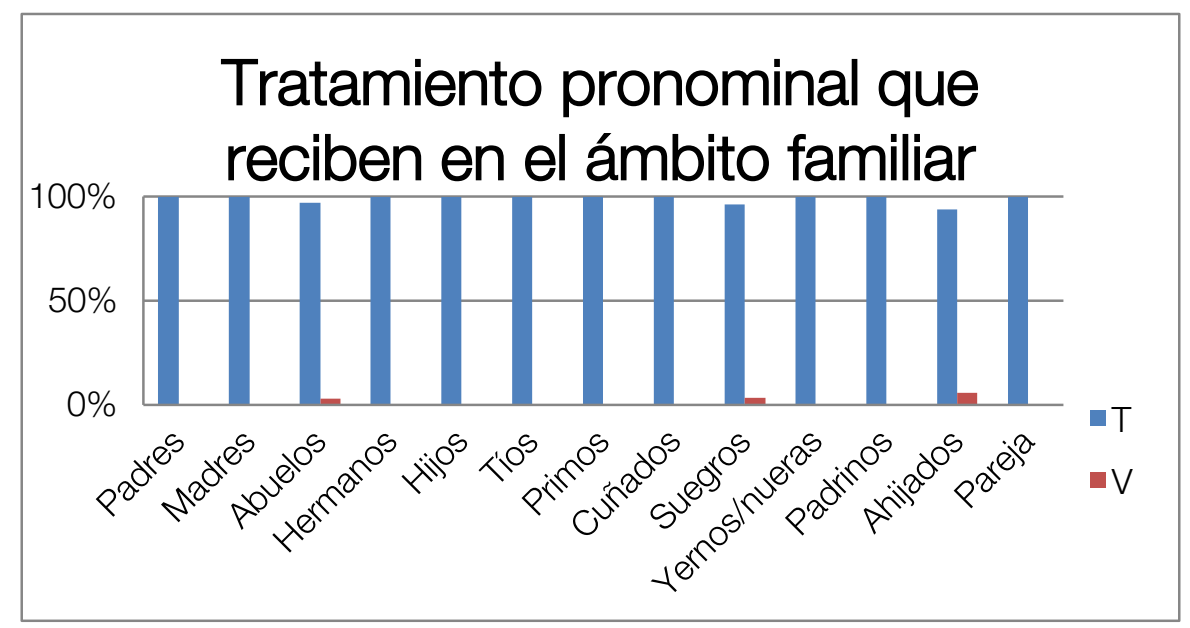

Gráfico 2: Trato pronominal que reciben los hablantes en el ámbito familiar

\section{2 Ámbito social}

En el ámbito social, al igual que en el familiar, distinguimos dos ejes sobre los que se sientan los tratamientos; por un lado, un eje simétrico dentro del cual encontramos relaciones como las que mantienen amigos cercanos o simples conocidos; y por otro, un eje asimétrico con las relaciones que se producen dentro de la sociedad con los diferentes cargos que la forman. Por ejemplo, con los camareros, dependientes o carteros se establece una relación no solidaria en la que nosotros estamos en un grado superior porque ellos se encargan de atender una de nuestras necesidades mientras que con los médicos, los curas o los policías se crea también una relación no solidaria pero a la inversa ya que estos interlocutores tienen un estatus social superior al nuestro.

Dentro del primer grupo, lo más común es el trato con T salvo que entre hablante e interlocutor existan diferencias de tipo generacional importantes cuando se preferirá un $\vee(19,4 \%)$ mutuo, aun así no es de extrañar dicha distinción pues se produce en hablantes de tercera generación que han conocido un sistema asimétrico de relaciones aún vigente en el que «a veces la amistad se hizo entrañable y, sin embargo, no pasamos nunca del usted» (Alonso 1968: 265). Así mismo lo señala Hernández Alonso (1970: 272): «Entre amigos lo normal es el tuteo, lo que no obsta para que exista, en ocasiones, un trato de usted, cuando la edad de los hablantes es muy distante.»

En el caso de las relaciones con los amigos de sus familiares, todo dependerá, en primer lugar, de la distancia generacional entre ellos y los hablantes y, en segundo lugar, del grado de confianza existente entre ambos. Lo mismo ocurre con conocidos o vecinos de los susodichos.

En cuanto al eje asimétrico, es importante distinguir el trato que se otorga a quien se encontraría, en una situación social determinada, en un grado inferior de la escala social y a quien, por el estatus que la sociedad le proporciona, se encuentra ya en un grado superior. Los primeros: carteros, empleados de banco, funcionarios, camareros, taxistas, etc.; son tratados mayoritariamente con $\mathrm{V}$ si el grado de confianza entre ellos y el hablante es mínimo (18\%) o si se encuentran generacionalmente distanciados (17,5\%). Los segundos: curas, monjas, médicos, policías, alcaldes y concejales, son tratados con $\mathrm{V}(79,6 \%)$, incluso cuando hay un alto grado de confianza. Excepto con los concejales, con el resto se tiene conciencia del poder social que poseen y así lo manifiestan 
los hablantes en su tratamiento. Solo las generaciones más jóvenes y los hablantes con nivel superior de enseñanza -como pasaba con la familia- muestran cierto disentimiento al respecto.

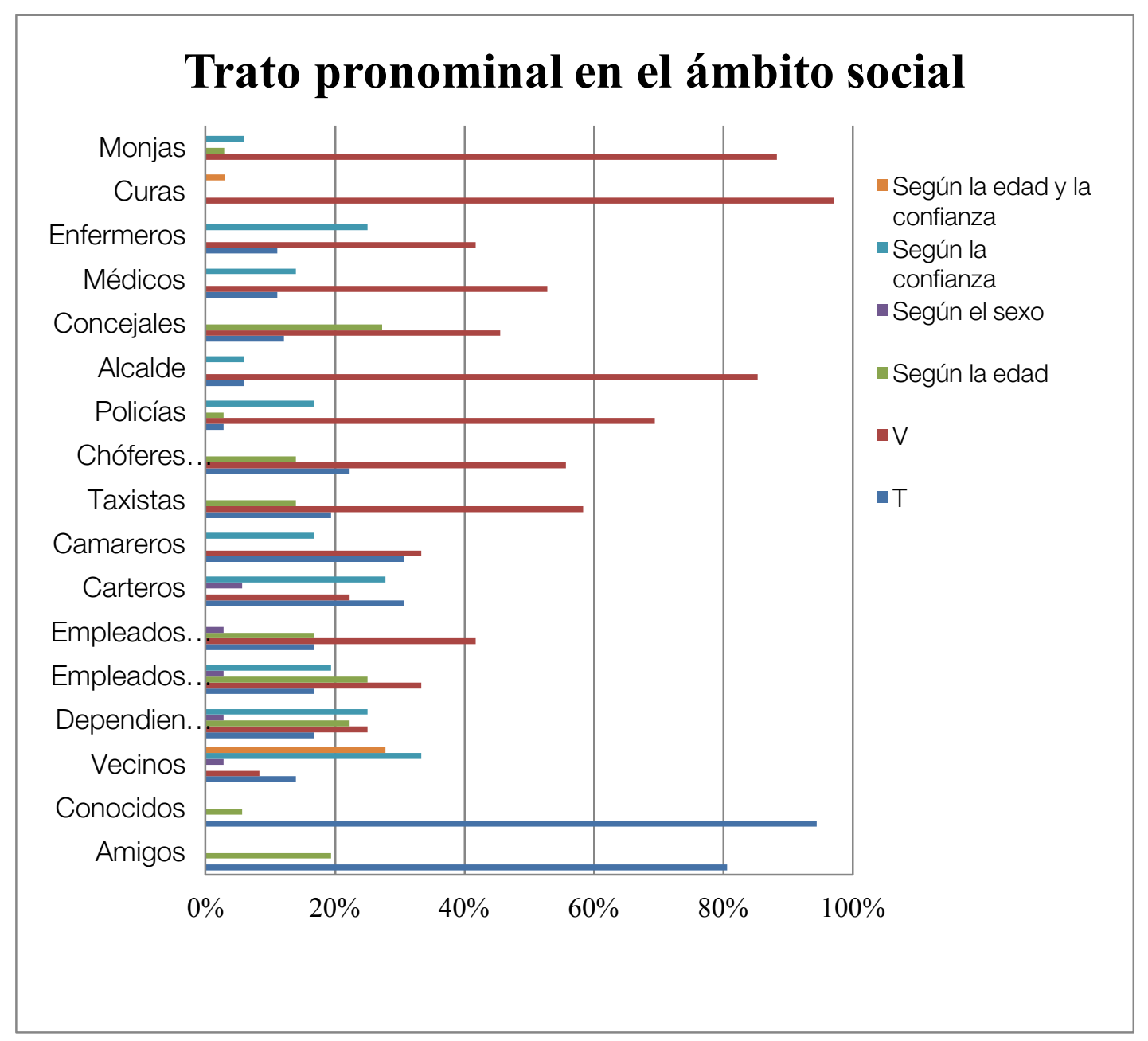

Gráfico 3: Trato pronominal en el ámbito social

El médico es la figura que más respeto impone a los hablantes $(33,3 \%)$, primero porque son conscientes del esfuerzo y responsabilidad que conlleva su profesión y, segundo, porque se encargan de una de las cosas que más valoran los hablantes: su salud. Así, cuando hablan con él, los hablantes "se ven en la necesidad de actuar disfrazados, incluso lingüísticamente», según dice Briz (2001: 16).

Para ocultar su identidad lingüística, el hablante -especialmente de niveles socioculturales bajos usa y abusa del fenómeno de la ultracorrección (Alvar 1972: 221) para rebajar su inseguridad idiomática y aparentar ser de un grupo social superior al suyo.

\section{3 Ámbito laboral}

Existe cierta falta de solidaridad dentro del ámbito laboral pero no se debe tanto a la distancia social entre los individuos que aquí se comunican como a una distancia generacional o afectiva entre ellos. Así pues, de los informantes encuestados, únicamente los de la tercera generación y los de nivel educacional bajo mantienen relaciones asimétricas con sus jefes y clientes y simétricas con sus compañeros. El resto varía para los tres interlocutores el uso de $T$ y $V$ en función de factores como la edad $(25,8 \%)$ o la confianza $(22,6 \%)$ determinando el carácter igualitario o solidario de dichas relaciones. Lo mismo ocurre a la inversa, los jefes o compañeros devuelven un trato pronominal motivado por la distancia de edad o de trato. 


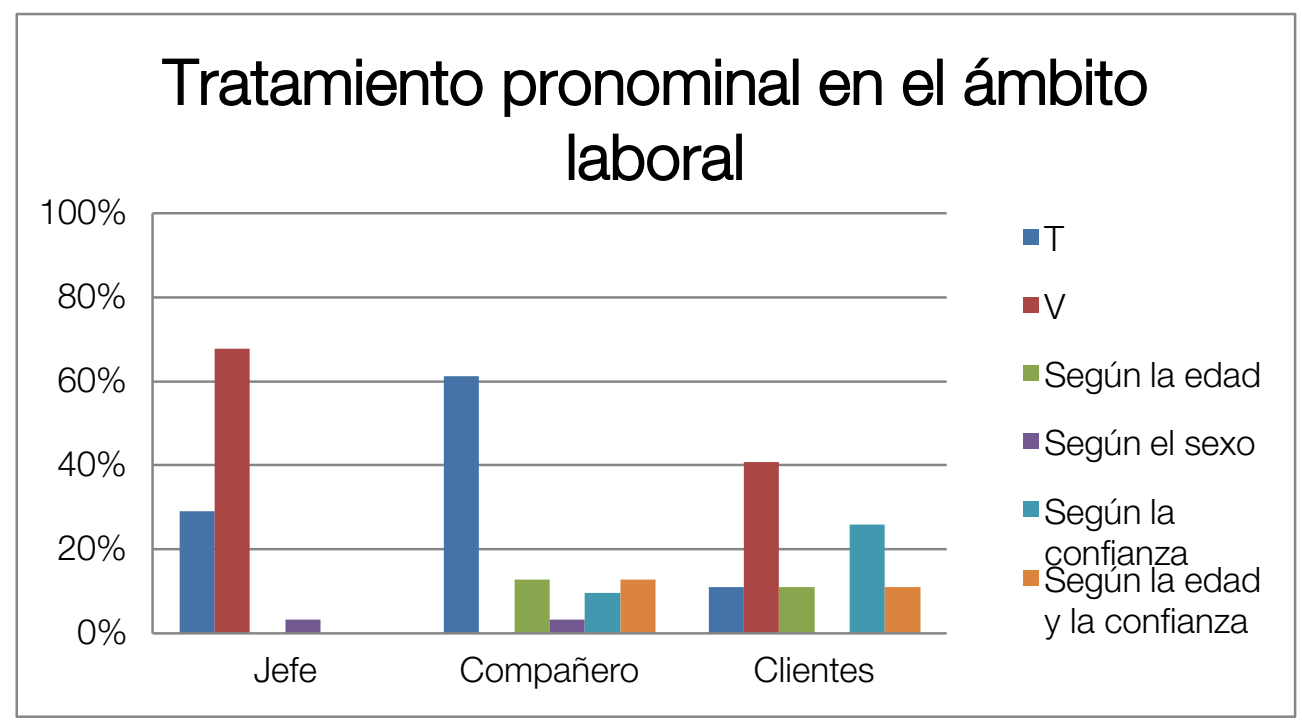

Gráfico 4: Trato pronominal el ámbito laboral

El sistema nominal, en cambio, sigue siendo, como en los otros ámbitos comentados, el discordante en la evolución de un sistema simétrico de relaciones. Los compañeros sí que se intercambian el mismo trato -ya sea nombres de pila, apodos o apellidos-, sin embargo, los jefes y subalternos difieren el suyo. Los primeros ofrecen a los segundos el nombre de pila o su apellido (90,3\%) mientras los segundos emplean mayoritariamente nombres de tratamiento como don o señor seguidos de un nombre propio (39,5\%). En algunos pocos casos -coincidiendo nuevamente con hablantes de primera generación o nivel sociocultural alto- se emplea recíprocamente el nombre de pila.

\section{4 Ámbito escolar}

En este contexto, lo común es ustedear al profesor, al director o decano y al secretario del centro y tutear a los compañeros de clase y a los camareros de la cafetería. Por tanto, se mantiene vigente un sistema asimétrico de relaciones donde prevalece el estatus o poder impuesto a los hablantes por su cargo, especialmente en la relación docente-alumno. Aun así, el número de hablantes que usa T $(30,5 \%)$ en la primera generación es muy significativo y revelaría un posible cambio que aún está por producirse en este tipo de relaciones.

En el tratamiento nominal es importante la utilización que se hace del título del oficio de educador en función del nivel de enseñanza. Para los primeros niveles se prefiere maestro para los hombres (24\%) y seño o señorita para las mujeres (16\%), en el nivel medio es común el uso de profesor o la forma apocopada profe (11\%) pero, sobre todo, el del nombre de pila (56,8\%), igual que ocurre en el ámbito universitario (29,2\% prefiere profesory un $25 \%$ el nombre de pila). Este comportamiento implicaría la existencia de un sistema de tratamientos generacional y socioculturalmente vinculante.

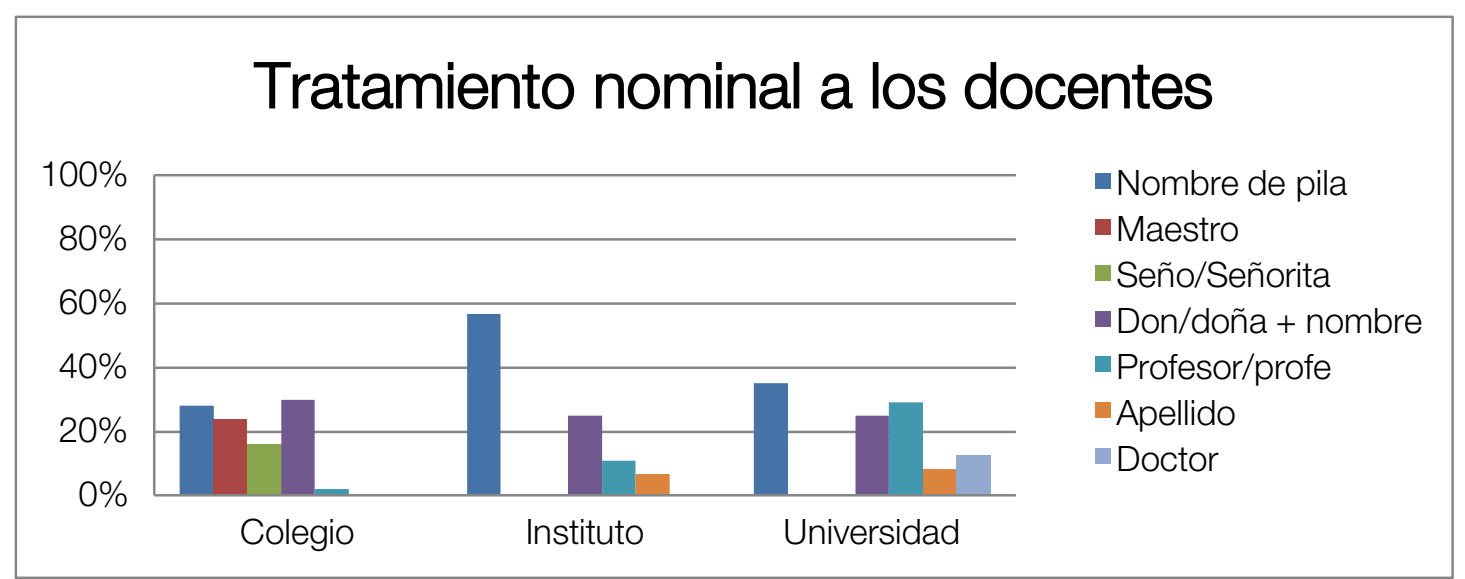

Gráfico 5: Trato nominal a los docentes según el tipo de centro 
Tras la exposición de nuestra investigación, han resultado verídicos algunos de los planteamientos inicialmente propuestos y refutables otros.

Por un lado, debemos rechazar la hipótesis sobre el uso mayoritario de $T$ frente a $V$ pues ambas formas pronominales son igualmente empleadas por los hablantes. Sin embargo, sí es cierto que el uso de T hacia diversos interlocutores ya sean padres, tíos, maestros o jefes, es mayor en hablantes jóvenes y de nivel educacional alto- no tanto así en las mujeres, como proponíamos en un primer momento, pues estas se muestran, en general, mucho más conservadoras que los hombres, lo que contradice los presupuestos de Alonso (1968) o da Silva (2006). En esta localidad canaria son los hablantes varones quienes se sitúan en la vanguardia de los cambios que comentamos. Esto puede deberse, entre otras razones, a la tardía incorporación de las mujeres a una sociedad en evolución donde aún hoy un alto porcentaje de ellas se mantiene al cargo del servicio doméstico y la crianza de los hijos u ocupan puestos mal remunerados en el sector servicios. Con el tiempo, una posible vía de investigación sería analizar el comportamiento de las mujeres que forman parte hoy de la primera generación y que han recibido una formación mucho más igualitaria que sus predecesoras. Por otro lado, podemos verificar la vigencia de un sistema asimétrico de tratamientos, especialmente en los ámbitos social, escolar y laboral, y mucho más visible en las formas nominales que en las pronominales. Esto ocurre por la conservación de un conjunto amplio de relaciones de poder que provocan que siga siendo mayoritario el uso de formas de parentesco o nombres de edad para llamar o referirse a los padres, jefes o maestros. Igualmente se conserva el uso de las formas de respeto don o señor para estos mismos y para los desconocidos, siendo especialmente significativo el uso de don en esta localidad. Sin embargo, es imposible negar la rápida evolución que ha sufrido el sistema a favor de las relaciones solidarias como vaticinaban Brown y Gilman (1960). Esto se refleja en el intercambio mutuo de $T$ entre profesores y discentes o de $V$ entre jefes y empleados, sobre todo en la primera generación, y en el aumento del uso del nombre de pila para llamar a padres o abuelos por parte del mismo grupo etario.

\section{REFERENCIAS BIBLIOGRÁFICAS}

Alba de Diego, Vidal y Jesús Sánchez Lobato (2009): «Tratamiento y juventud en la lengua hablada: aspectos sociolingüísticos», en Alba de Diego, Vidal et alii, eds., Aspectos del español actual: descripción, enseñanza y aprendizaje (L1 y L2), Madrid, SGEL, 11-41.

Alcina Franch, Juan y José Manuel Blecua (1982): Gramática española, Barcelona, Ariel.

Almeida Suárez, Manuel y Juana Rodríguez Mendoza (1994): «Formas pronominales de tratamiento en español actual», en Stolidi, Jeanine, ed., Recherches en Lingüistique Hispanique: Actes du colloque d'Aix-enProvence (20-21 Mars 1992), Aix-en-Provence, Université de Provence, 167-168.

Almeida Suárez, Manuel y Juana Rodríguez Mendoza (2006): «Variación y cambio en el sistema pronominal de trato: el caso de San Sebastián de La Gomera», en Luque Durán, Juan de Dios, ed., Actas del V Congreso andaluz de Lingüística general. Homenaje al profesor José Andrés Molina Redondo, Granada, Método, 257-267.

Alonso y Fernández de las Redondas, Dámaso (1968): «La muerte del usted», Del Siglo de Oro a este siglo de siglas, Madrid, Gredos, 264267.

Alvar López, Manuel (1959): El español hablado en Tenerife, Madrid, Consejo Superior de Investigaciones Científicas.
Alvar López, Manuel (1972): Niveles socioculturales en el habla de Las Palmas de Gran Canarias, Las Palmas de Gran Canaria, Cabildo Insular de Gran Canaria.

Beinhauer, Werner (1963): El español coloquial, Madrid, Gredos.

Beinhauer, Werner (1968): El español coloquial, Madrid, Gredos.

Blas Arroyo, José Luis (1995): «Un ejercicio de sociolingüística interaccional: el caso de los pronombres de tratamiento en el español actual», en Verba: Anuario Galego de Filoloxía, 22, 229-252.

Bosch Caballero, $M^{a}$ del Carmen (1985): «Hacia un estudio sociolingüístico de la variedad de lengua canaria», Giniguada, 2, 163-168.

Brown, Robert y Albert Gilman (1960): "The pronouns of Power and Solidarity", en Sebeok, T. A., ed., Style in Language, Cambridge, MIT, 253-276.

Briz Gómez, Antonio (2001): El español coloquial en la conversación: esbozo de pragmagramática, Barcelona, Ariel.

Carricaburo, Norma (1997): Las fórmulas de tratamiento en el español actual, Madrid, Arco Libros, 50-56.

Fontanella de Weinberg, $M^{a}$ Beatriz (1999): "Sistemas pronominales de tratamiento usados en el mundo hispánico", en Del Bosque, Ignacio y Violeta Demonte, dirs., 
Gramática descriptiva de la lengua española, vol. 1, Madrid, Espasa Calpe, 1399-1425.

Havertake, Henk (1994): La Cortesía verbal. Estudio pragmalingüístico, Madrid, Gredos, 11-49.

Hernández Alonso, César (1970): «Las formas de tratamiento", Sintaxis española, Valladolid, Industrial Litográfica, 271-273.

Historia (s.a.), [fecha de consulta: 15 de mayo de 2014] de <http://www.tenerifelaorotava.com/sp/history.aspx>.

INE (Instituto Nacional de Estadística), Cifras oficiales de población resultantes de la revisión del Padrón municipal a 1 de enero de 2013 [en línea], [fecha de consulta: 20 de enero de 2014], disponible

en $<$ http://www.ine.es/jaxi/menu.do?type=pcaxis \&path $=\% 2 \mathrm{Ft} 20 \% 2 \mathrm{Fe} 260 \% 2 \mathrm{Fa} 2013 \% 2 \mathrm{~F} \&$ file $=$ pcaxis $\& N=\& L=0>$.

La Orotava. Datos demográficos (s.a.), [fecha de consulta: 20 de enero de 2014] de <http://www.tenerifevioleta.es/diagnosticonec esidades/pdf \%20municipios/LA \%20OROTAV A.pdf>.

Lapesa Melgar, Rafael (1970): «Personas gramaticales y tratamientos en español», en Revista de la Universidad de Madrid, 74, 167193.

Lázaro Carreter, Fernando (1997): «Jefe», El dardo en la palabra, Barcelona, DeBolsillo, 429-431.

López Vallejo, Ma Ángeles (2010): «Algunas fórmulas de tratamiento del ámbito familiar en los repertorios lexicográficos», en Hummel, Martin et alii, eds., Formas y fórmulas de tratamiento en el mundo hispánico, México, El Colegio de México, 571-594.

Marcos Marín, Francisco (1972): «Fórmulas de tratamiento en español», Aproximación a la gramática española, Madrid, Cincel, 146-149.

Medina López, Javier (1989/90): «Formas de tratamiento en una comunidad juvenil», en Revista de Filología de la Universidad de La Laguna, 8-9, 249-258.

Medina López, Javier (1990): «Sobre los conceptos de poder y solidaridad en las formas de tratamiento", en Álvarez Martínez, $\mathrm{M}^{\mathrm{a}}$ Ángeles, ed., Actas del Congreso de la Sociedad Española de Lingüística, $X X$ Aniversario, Madrid, Editorial Gredos, 2, 630638.

Medina López, Javier (2010): «Panorama sobre el estudio de las formas de tratamiento en el español de Canarias", en Hummel, Martin et alii, eds., Formas y fórmulas de tratamiento en el mundo hispánico, México, El Colegio de México, 224-246.

Medina Morales, Francisca (2010): «La metodología en los estudios sobre formas y fórmulas de tratamiento en español», Hummel, Martin et alii, eds., Formas y fórmulas de tratamiento en el mundo hispánico, México, El Colegio de México, 21-56.

Morera Pérez, Marcial (1990): Lengua y colonia en Canarias, La Laguna, Editorial Globo.
Morera Pérez, Marcial (1991): «Diminutivos, apodos, hipocorísticos, nombres de parentesco y nombres de edad en el sistema de tratamientos populares de Fuerteventura (Canarias)", Formación del vocabulario canario, Tenerife, Centro de la Cultura Popular Canaria, pp. 219-244.

Paredes García, Florentino (2010): «¿Es factible un cuestionario estándar para el estudio del tratamiento?: la experiencia del proyecto PRESEEA en Madrid y Alcalá de Henares", en Hummel, Martin et alii, eds., Formas y fórmulas de tratamiento en el mundo hispánico, México, El Colegio de México, 163-194.

RAE (2009): Nueva gramática de la lengua española, Madrid, Espasa.

Rodríguez Mendoza, Juana (1993): Tratamiento pronominal en San Sebastián de La Gomera: estudio sociolingüístico, Memoria de licenciatura inédita, Facultad de Filología, Universidad de La Laguna.

Silva, Antonio da (2006): «Formas de tratamiento familiares», en Casado Velarde, Manuel et alii, eds., Análisis del discurso: Lengua, cultura, valores. Actas del I Congreso Internacional (Pamplona, noviembre de 2002), Madrid, Arco Libros, 2, 2171-2184. 
Sistema de tratamiento en el español de Canarias. Estudio sociolingüístico en una comunidad semiurbana | Natalia Ruiz 